\title{
Damage Level Prediction of Reinforced Concrete Building Based on Earthquake Time History Using Artificial Neural Network
}

\author{
Reni Suryanita ${ }^{1, *}$, Harnedi Maizir ${ }^{2}$, Enno Yuniarto ${ }^{1}$, Muhamad Zulfakar ${ }^{1}$, and Hendra \\ Jingga ${ }^{1}$ \\ ${ }^{1}$ Department of Civil Engineering, Faculty of Engineering, University of Riau, Pekanbaru, Indonesia \\ ${ }^{2}$ Department of Civil Engineering, Sekolah Tinggi Teknologi Pekanbaru, Indonesia
}

\begin{abstract}
The strong motion earthquake could cause the building damage in case of the building not considered in the earthquake design of the building. The study aims to predict the damage-level of building due to earthquake using Artificial Neural Networks method. The building model is a reinforced concrete building with ten floors and height between floors is $3.6 \mathrm{~m}$. The model building received a load of the earthquake based on nine earthquake time history records. Each time history scaled to $0,5 \mathrm{~g}$, $0,75 \mathrm{~g}$, and $1,0 \mathrm{~g}$. The Artificial Neural Networks are designed in 4 architectural models using the MATLAB program. Model 1 used the displacement, velocity, and acceleration as input and Model 2 used the displacement only as the input. Model 3 used the velocity as input, and Model 4 used the acceleration just as input. The output of the Neural Networks is the damage level of the building with the category of Safe (1), Immediate Occupancy (2), Life Safety (3) or in a condition of Collapse Prevention (4). According to the results, Neural Network models have the prediction rate of the damage level between $85 \%-95 \%$. Therefore, one of the solutions for analyzing the structural responses and the damage level promptly and efficiently when the earthquake occurred is by using Artificial Neural Network
\end{abstract}

\section{Introduction}

Indonesia is one of the countries located in the high seismic region. Some locations in Indonesia were struck by massive ground motion, such as Aceh City (9.3 Ritcher scale) which was followed by a tsunami at December 26th, 2004. At 2005, Nias Island was struck by 8.7 Richter scale earthquake along with tsunami. At May 27th, 2006, a 5.9 Ritcher scale earthquake hit Yogyakarta City which leads to property damage and casualties. At September 30th, 2009 a 7.9 Ritcher scale earthquake hit Padang City with tsunami possibility (1). The design of structure building needs to consider the risk of the loss due to an earthquake.

* Corresponding author: reni.suryanita@eng.unri.ac.id 
The risk-targeted ground motions for Indonesia based on the Indonesian Earthquake Resistance Building Code SNI 1726-2012. Seismic loading could significantly impact the structural behavior of building. Therefore it is necessary to investigate the behavior and responses of the building structure under seismic loading.

There are two methods to analyze the responses of a structure due to the earthquake, the response spectrum and time history method (2). Time history analysis is the best used for irregular building structure under seismic loading. The study observed the influence of earthquake loading on the building structure over some duration of time history analysis results. However, the analysis process of non-linear time history taken a long time. To quickly analyze the damage level of building due to the earthquake, an Artificial Intelligent method is applicable. Therefore, this research aims to predict the damage level of the structure under seismic loading using Artificial Neural Network (ANN) technique.

The previous studies stated the Artificial Neural Networks could predict the health of the structure by routinely monitoring (3), (4) and, (5). Artificial Neural Network's algorithm is analogous to human's adaptive neural network which is capable of learning through a set of data with a variable pattern. Moreover, the accuracy of the ANN prediction indicated the accuracy of the provided data in the learning process (6).

The prediction of the behavior of the structure under seismic loading could help the occupants of the building to act prudently when an earthquake occurs. The prediction or output parameter of the ANN model is the performance or damage level of the building structure during an earthquake. Based on FEMA 356 (7), the performance level criteria (Fig.1) are as follows:

1. Fully operational (FO): the building is in fully functional state after the earthquake. The structural have the damage and minor nonstructural damage.

2. Immediate occupancy (IO): the building structure is still safe to functionally operate after the earthquake. There is minor damage with insignificant impact on the occupant of the building. The building could be used directly after the quake.

3. Life safety (LS): the building structure suffers from medium damage which requires rehabilitation. However, the building is still stable and safe for the occupants.

4. Collapse prevention (CP): the building is severely damaged. Nonstructural components collapse and the building is no more useable (operational state).

Fig. 1 describes the performance level criteria based on the displacement and force subject to the structure.

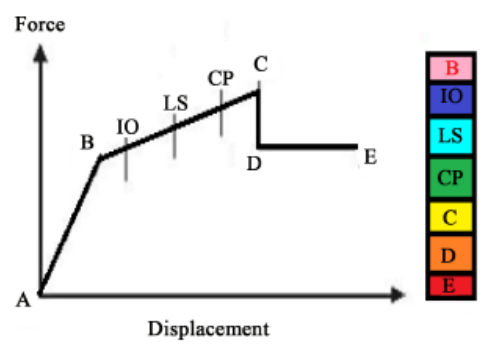

Fig.1. Performance level criteria of building 


\section{Artificial Neural Networks}

The knowledge related to the biological neural network has inspired the development of Artificial Neural Network (ANN) computation method. The data classification, cluster, and non-parametric regression or to simulate the process in the biological neural network need the architecture and operation of ANN. The ANN system comprises of interconnected processing units (neurons) which work simultaneously to provide a solution based on the purpose of the ANN model.

ANN training process is performed to develop the memory and generalization capability of the ANN system. The ANN memorizes how to solve the problem based on the provided learning dataset. The generalization capability means the ANN can recognize the similar pattern (not identical) and provide an output based on the learning phase [8].

The relationship or connection between neurons could determine the quality of the output given by an ANN system (8). The neuron layer stored interconnected neurons. There are three layers in an ANN mode:

1. Input layer, the neurons in the input layer is used to store input data which represents the problem to be solved.

2. Hidden layer, the neurons in hidden layer could not be observed directly and is used to improve the ability of the ANN system to predict a nonlinear relationship between input and output parameters.

3. Output layer, the neurons in the output layer is used to store output data which is the solution provided by the ANN system.

Multilayer perceptron has at least three layers, an input layer, hidden layer, and an output layer. The advantage of multilayer perceptron over single layer ANN is the improved ability to solve complex and nonlinear problems.

There are two criteria used to evaluate the performance and error rate of an ANN system, Correlation Coefficient (R) and Mean Square Error (MSE). The correlation coefficient is the measure of statistic covariance or association between two variables. The ratio between the predicted output value and target (actual) output value indicated R-value. The equation following is the R-value for the ANN model.

$$
R=\frac{\sum x y}{\sqrt{\sum x^{2} \sum y^{2}}}
$$

where :

$$
\begin{array}{ll}
\mathrm{X} & =\mathrm{X}-\mathrm{X}^{\prime} \\
\mathrm{y} & =\mathrm{Y}-\mathrm{Y}^{\prime} \\
\mathrm{X} & =\text { observed value (target) } \\
\mathrm{X}, & =\text { average of } \mathrm{X} \\
\mathrm{Y} & =\text { prediction value (output) } \\
\mathrm{Y}, & =\text { average of } \mathrm{Y}
\end{array}
$$

Interprete the strength of relationship between two variables :

$$
\begin{array}{ll}
\mathrm{R}=0 & : \text { no correlation } \\
0<\mathrm{R} \leq 0,25 & : \text { poor correlation } \\
0,25<\mathrm{R} \leq 0,50 & : \text { medium correlation } \\
0,50<\mathrm{R} \leq 0,75 & : \text { strong correlation } \\
0,75<\mathrm{R} \leq 0,99 & : \text { very strong correlation } \\
\mathrm{R}=1 & \text { : perfect correlation }
\end{array}
$$




\section{Methodology}

\subsection{Data of Structure and Loading}

The building structure model is the 10-story building with identical floor plan from base to rooftop as shown in Fig. 2. The story height is $3.6 \mathrm{~m}$. The building geometry is symmetrical about the $\mathrm{X}$ and $\mathrm{Y}$ axis. There are six bays, and each bay spans 5 meters. The rebar material has yield strength, fy $=240 \mathrm{MPa}$ and the ultimate strength, $\mathrm{fu}=400 \mathrm{MPa}$. The dimension of the structural element is as follows:

1. Beam:50 × $70 \mathrm{~cm}^{2}, f_{c}{ }^{\prime}=30 \mathrm{Mpa}$

2. Column: $80 \times 80 \mathrm{~cm}^{2}, f_{c}^{\prime}=30 \mathrm{Mpa}$

3. Floor-slab: $20 \mathrm{~cm}$-thick, $f_{c}{ }^{\prime}=30 \mathrm{Mpa}$

4. Shear wall: $25 \mathrm{~cm}$-thick, $f_{c}{ }^{\prime}=30 \mathrm{Mpa}$

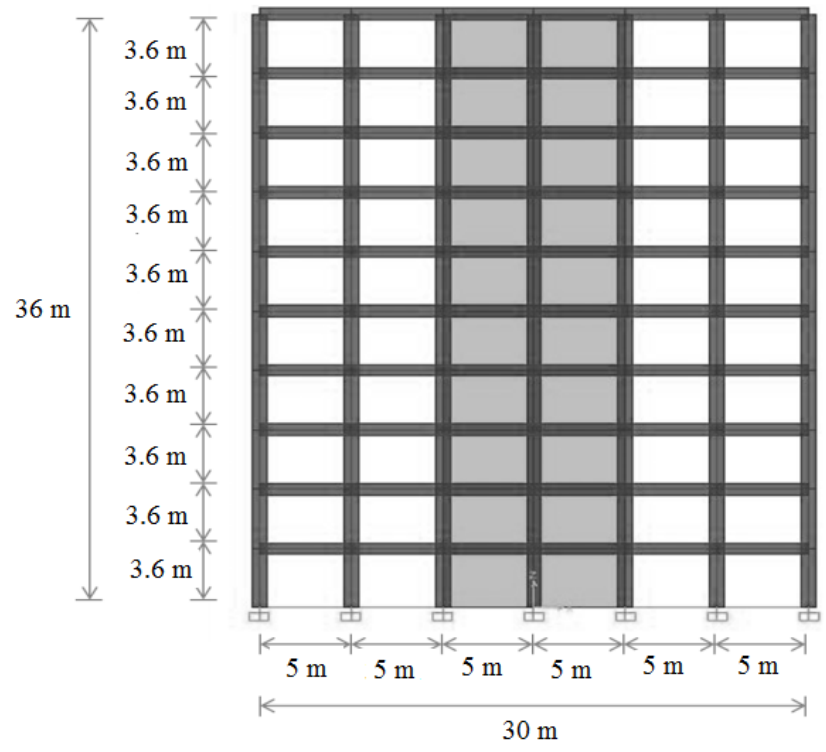

Fig. 2. Ten-story building model

There are nine earthquake-records are used in this study. The list of the earthquake time history is as follows:

$1 \quad$ New Zealand $(\mathrm{PGA}=0,255 \mathrm{~g})$

2 San Fransisco $(\mathrm{PGA}=0,095 \mathrm{~g})$

3 Cape Mendocino $(\mathrm{PGA}=0,15 \mathrm{~g})$

4 El Centro $(\mathrm{PGA}=0,319 \mathrm{~g})$

$5 \quad$ Loma Prieta $(\mathrm{PGA}=0,12 \mathrm{~g})$

6 San Fernando $(\mathrm{PGA}=0,028 \mathrm{~g})$

$7 \quad$ Kocaeli, Turkey $(\mathrm{PGA}=0,01 \mathrm{~g})$

8 Nenana $(\mathrm{PGA}=0,004 \mathrm{~g})$

9 Denali, Alaska $(\mathrm{PGA}=0,008 \mathrm{~g})$ 


\subsection{ANN Training Phase}

The damage level of the 10-story building is predicted using Backpropagation multilayer ANN model. The ANN analysis was performed using MATLAB. The ANN testing phase was performed to investigate the prediction accuracy of the trained ANN model with new input data. The testing result will show the capability of the ANN model to predict structure damage level. The ANN model comprises of an input layer with nine neurons, a hidden layer with ten neurons, and an output layer with one neuron. The ANN training was performed by assuming the following training parameters:

1. Number of iteration $=3000$ epochs.

2. Target correlation coefficient $(\mathrm{R})=85 \%$.

The level based on structural response parameters during an earthquake. The input parameters are the structural responses: displacement, velocity, and acceleration. Meanwhile, the output neuron has four possible states: Safe, Immediate Occupancy (IO), Life Safety (LS), or Collapse Prevention (CP). Safe is coded with 1, IO with 2, LS with 3, and $\mathrm{CP}$ with 4.

Based on the time history analysis results, eight datasets are used for ANN training phase, whereas the remaining one dataset is used for ANN testing phase.

The ANN architecture was varied as tabulated in Table 1. Model 1 has displacement, velocity, and acceleration as input parameters, and damage level as the output parameter. Model 2, 3, and 4 has only one input, that is, displacement, velocity, or acceleration as the input parameter, respectively. The model variation was done to obtain performance comparisons between models with different input parameters.

Table 1. ANN Model

\begin{tabular}{|c|c|}
\hline ANN Model & Input Data \\
\hline Model 1 & Displacement, Velocity, Acceleration \\
\hline Model 2 & Displacement \\
\hline Model 3 & Velocity \\
\hline Model 4 & Acceleration \\
\hline
\end{tabular}

The datasets used for the ANN training phase are 9595 data as shown in Table 2. The source of the data is 8-time history analysis data: New Zealand, San Fransisco, Cape Mendocino, El Centro, Loma Prieta, San Fernando, Kocaeli and Nenana which are scaled to $0.5 \mathrm{~g}, 0.75 \mathrm{~g}$, and $1 \mathrm{~g}$. The type of the ANN model is Backpropagation ANN. The activation function was Sigmoid Biner. MATLAB program provided two sigmoid functions: Tan-Sigmoid function and Log-Sigmoid function (9). 
Table 2. Neural Networks Training Data Set for Displacement as Input

\begin{tabular}{|c|c|c|c|c|c|c|c|}
\hline \multirow{4}{*}{$\begin{array}{l}\text { No } \\
1\end{array}$} & \multirow{4}{*}{$\begin{array}{c}\text { Earthquake } \\
\\
\text { New Zealand } \\
0,5 \mathrm{~g} \\
\end{array}$} & \multirow{4}{*}{$\begin{array}{c}\text { Time } \\
\text { (Sec) } \\
0\end{array}$} & \multirow{2}{*}{\multicolumn{3}{|c|}{$\frac{\text { Input }}{\text { Displacement (m) }}$}} & \multirow{3}{*}{\multicolumn{2}{|c|}{$\begin{array}{l}\text { Output } \\
\text { Criteria } \\
\text { (Target) }\end{array}$}} \\
\hline & & & & & & & \\
\hline & & & \multirow{2}{*}{$\begin{array}{c}\begin{array}{c}\mathbf{X} \\
\text { direction }\end{array} \\
0.0000\end{array}$} & \multirow{2}{*}{$\begin{array}{c}\begin{array}{c}\mathbf{Y} \\
\text { direction }\end{array} \\
0.0000\end{array}$} & \multirow{2}{*}{$\begin{array}{c}\begin{array}{c}Z- \\
\text { direction }\end{array} \\
-0.0023\end{array}$} & & \\
\hline & & & & & & Safe & 1 \\
\hline 2 & $\begin{array}{c}\text { New Zealand } \\
0,5 \mathrm{~g}\end{array}$ & 0.05 & 0.0000 & 0.0000 & -0.0023 & Safe & 1 \\
\hline 3 & $\begin{array}{c}\text { New Zealand } \\
0,5 \mathrm{~g}\end{array}$ & 0.1 & 0.0000 & 0.0000 & -0.0023 & Safe & 1 \\
\hline 4 & $\begin{array}{c}\text { New Zealand } \\
0,5 \mathrm{~g}\end{array}$ & 0.15 & 0.0000 & 0.0000 & -0.0023 & Safe & 1 \\
\hline 5 & $\begin{array}{c}\text { New Zealand } \\
0,5 \mathrm{~g}\end{array}$ & 0.2 & 0.0000 & 0.0000 & -0.0023 & Safe & 1 \\
\hline$\vdots$ & $\vdots$ & $\vdots$ & $\vdots$ & $\vdots$ & $\vdots$ & $\vdots$ & $\vdots$ \\
\hline 9591 & Nenana & 29.8 & 0.0017 & 0.0007 & -0.0023 & $I O$ & 2 \\
\hline 9592 & Nenana & 29.85 & 0.0050 & 0.0018 & -0.0023 & $I O$ & 2 \\
\hline 9593 & Nenana & 29.9 & 0.0075 & 0.0026 & -0.0024 & $I O$ & 2 \\
\hline 9594 & Nenana & 29.95 & 0.0088 & 0.0030 & -0.0024 & $I O$ & 2 \\
\hline 9595 & Nenana & 30 & 0.0090 & 0.0030 & -0.0024 & $I O$ & 2 \\
\hline
\end{tabular}

\section{Results}

The Artificial Neural Networks input parameters are structure displacement, velocity, and acceleration, whereas the ANN model predicted the output parameter is the damage level (Safe, IO, LS, CP. Fig 3 shows the calculated R-value 0.94712, which indicates the prediction value closely matches the target value. Therefore it is concluded that the prediction performance of the ANN model is highly accurate and strongly correlated.

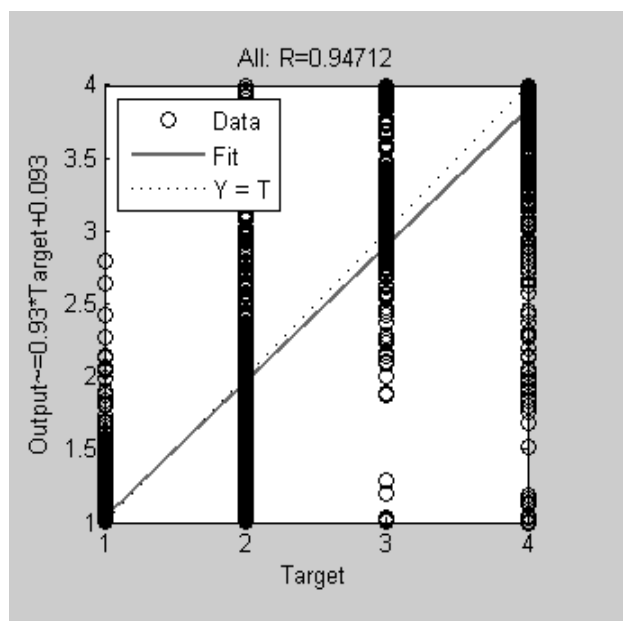

Fig. 3. R Plot for ANN Model 1 
The ANN training results for the other ANN models are tabulated in Table 3. Based on Table 3, Model 1 has the best prediction, whereas the worst model is Model 4 with acceleration (X, Y, and $\mathrm{Z}$ direction) as the input.

Table 3. ANN performance for all ANN models

\begin{tabular}{|c|c|c|}
\hline NN Model & MSE & R \\
\hline Model 1 & 0,11088 & 0,94712 \\
\hline Model 2 & 0,10924 & 0,93841 \\
\hline Model 3 & 0,23407 & 0,86543 \\
\hline Model 4 & 0,33196 & 0,79339 \\
\hline
\end{tabular}

The results of the ANN testing phase for Model 1 are tabulated in Table 4. The Correlation Regression, $\mathrm{R}$ of model 1 is 0.94712 based on 913 data. It means the results are correctly predicted, whereas the remaining 61 data $(7.15 \%)$ are wrongly predicted.

Table 4. ANN Model 1 Testing Process

\begin{tabular}{|c|c|c|c|c|c|c|c|c|}
\hline \multirow{2}{*}{$\begin{array}{c}\text { No. } \\
1 \\
\end{array}$} & \multirow{2}{*}{$\begin{array}{l}\text { Time History } \\
\text { Danieli 0,5g } \\
\end{array}$} & \multirow{2}{*}{$\begin{array}{c}\begin{array}{c}\text { Time } \\
\text { (second) }\end{array} \\
0\end{array}$} & \multicolumn{2}{|c|}{$\begin{array}{c}\text { Target } \\
\text { Category }\end{array}$} & \multicolumn{3}{|c|}{ Prediction Result } & \multirow{2}{*}{$\begin{array}{l}\text { Status } \\
\text { Match }\end{array}$} \\
\hline & & & SAFE & 1 & 1.019 & 1 & SAFE & \\
\hline 2 & Danieli $0,5 \mathrm{~g}$ & 0.05 & SAFE & 1 & 1.0175 & 1 & SAFE & Match \\
\hline 3 & Danieli $0,5 \mathrm{~g}$ & 0.1 & SAFE & 1 & 1.0245 & 1 & SAFE & Match \\
\hline$\vdots$ & $\vdots$ & $\vdots$ & $\vdots$ & $\vdots$ & $\vdots$ & $\vdots$ & $\vdots$ & $\vdots$ \\
\hline 69 & Danieli $0,5 \mathrm{~g}$ & 3.4 & IO & 2 & 1.7978 & 2 & IO & Match \\
\hline 70 & Danieli 0,5g & 3.45 & $I O$ & 2 & 2.0011 & 2 & $I O$ & Match \\
\hline 71 & Danieli 0,5g & 3.5 & IO & 2 & 1.9602 & 2 & $I O$ & Match \\
\hline 72 & Danieli 0,5g & 3.55 & IO & 2 & 1.4088 & 1 & SAFE & False \\
\hline 73 & Danieli $0,5 \mathrm{~g}$ & 3.6 & IO & 2 & 1.4343 & 1 & SAFE & False \\
\hline$\vdots$ & $\vdots$ & $\vdots$ & $\vdots$ & $\vdots$ & $\vdots$ & $\vdots$ & $\vdots$ & $\vdots$ \\
\hline 85 & Danieli 0,5g & 4.2 & $L S$ & 3 & 3.3426 & 3 & $L S$ & Match \\
\hline 86 & Danieli 0,5g & 4.25 & $L S$ & 3 & 3.8801 & 4 & $C P$ & False \\
\hline 87 & Danieli $0,5 \mathrm{~g}$ & 4.3 & $L S$ & 3 & 3.8644 & 4 & $C P$ & False \\
\hline 88 & Danieli 0,5g & 4.35 & $L S$ & 3 & 3.2352 & 3 & $L S$ & Match \\
\hline$\vdots$ & $\vdots$ & $\vdots$ & $\vdots$ & $\vdots$ & $\vdots$ & $\vdots$ & $\vdots$ & $\vdots$ \\
\hline 911 & Danieli 1g & 29.9 & SAFE & 1 & 1.014 & 1 & SAFE & Match \\
\hline 912 & Danieli 1g & 29.95 & SAFE & 1 & 1.0239 & 1 & SAFE & Match \\
\hline 913 & Danieli $1 \mathrm{~g}$ & 30 & SAFE & 1 & 1.0418 & 1 & SAFE & Match \\
\hline
\end{tabular}


The analog with Model 1, the process was performed for the other ANN models, which results are shown in Table 5.

Table 5. ANN Testing Phase Summary

\begin{tabular}{|c|c|c|c|}
\hline \multirow{2}{*}{ ANN Model } & \multicolumn{2}{|c|}{ Prediction } & \multirow{2}{*}{$\begin{array}{c}\text { Percentage } \\
\text { Matching }\end{array}$} \\
\cline { 2 - 3 } & Match & False & 0,94712 \\
\hline Model 1 & 852 & 61 & 0,93841 \\
\hline Model 2 & 841 & 72 & 0,86543 \\
\hline Model 3 & 835 & 78 & 0,79939 \\
\hline Model 4 & 800 & 113 & \\
\hline
\end{tabular}

According to Table 5, it can be concluded that Model 1 resulted in the best to predict the desired output with $95 \%$ of prediction matching percentage. Model 2 and Model 3 is also conducted above $85 \%$ of percentage matching as the target correlation coefficient (R). Meanwhile, the prediction accuracy of Model 4 is only $79 \%$ less than the target correlation coefficient, R. Therefore, the ANN model can predict the damage level of the building structure with the average prediction accuracy more than $90 \%$, which indicates good correlation.

\section{Conclusion}

According to the results, the ANN training phase by evaluating R-value concluded Model 1 has the best prediction accuracy. The input parameters used in Model 1 are structure displacement, velocity, and acceleration in X, Y, and Z direction. Meanwhile, Model 4 has the worst prediction accuracy with acceleration in $\mathrm{X}, \mathrm{Y}$, and $\mathrm{Z}$ direction as the only input parameter.

The prediction accuracy of all ANN models based on the ANN testing phase with 913 data sets, $95 \%$ of the data was predicted accurately by ANN Model 1, whereas for Model 2 , Model 3, and Model 4 the prediction accuracy was $94 \%, 86 \%$, and $80 \%$, respectively. The prediction accuracy of the ANN model was above $85 \%$, which indicates that the ANN model is highly accurate as a prediction tool.

The authors would like to thank the Ministry of Research, Technology and Higher Education (Kemenristekdikti), Indonesia, for funding this research through Fundamental Research Scheme 2017.

\section{References}

1. BMKG. Earthquake-Query Data [Internet]. BMKG Indonesia. 2017 [cited 2017 Jan 20]. Available from:

http://repogempa.bmkg.go.id/index.php?id=101\&session_id=zLImgAy7

2. Chopra AK. Dynamics of Structure, Theory and Applications to Earthquake Engineering. Prentice Hall; (2012)

3. Suryanita R, Maizir H, Jingga H. Prediction of Structural Response Based on Ground Acceleration Using Artificial Neural Networks. Int J Technol Eng Stud. 
(2017)

4. Suryanita R, Jingga H, Yuniarto E. The Application of Artificial Neural Networks in Predicting Structural Response of Multistory Building in The Region of Sumatra Island. KnE Eng [Internet]. 2016;1(2015):1-6. Available from: http://knepublishing.com/index.php/KnE-Engineering/article/view/526/1619

5. Chakraverty S, Marwala T, Gupta P. Response Prediction of Structure System Subject to Earthquake Motions using Artificial Neural Network. Asian J Civ Eng (Building Housing). Vol 7 (2006)

6. Gharehbaghi K. Artificial neural network for transportation infrastructure systems. MATEC Web Conf. (2016)

7. FEMA356. Prestandard and Commentary for The Seismic Rehabilitation of Buildings. Vol. FEMA 356. Federal Emergency Management Agency; (2000)

8. Rajasekaran S, Pai GAV. Neural Network, Fuzzy logic, and Genetic Algorithms Syntesis and Applications. New Delhi: Prentice Hall of India; (2007).

9. Demuth HB, Beale MH, De Jess O, Hagan MT. Neural network design. Martin Hagan; (2014). 